07

\title{
Высоковольтные (1600 V) размыкатели тока с субнаносекундным (150 ps) быстродействием на основе $4 \mathrm{H}$-SiC
}

\author{
() П.А. Иванов, О.И. Коньков, Т.П. Самсонова, А.С. Потапов \\ Физико-технический институт им. А.Ф. Иоффре РАН, Санкт-Петербург, \\ Россия \\ E-mail: Pavel.Ivanov@mail.ioffe.ru
}

Поступило в Редакцию 5 сентября 2017 г.

Изготовленные на основе эпитаксиальных $4 H$-SiC $p^{++}-p^{+}-p-n_{o}-n^{+}$-структур высоковольтные $(1600 \mathrm{~V})$ диоды испытаны в качестве быстродействующих размыкателей тока в составе специальной импульсной схемы. Измеренное время обрыва тока составляет около $150 \mathrm{ps}$. Такое время является рекордно коротким для высоковольтных (свыше $1000 \mathrm{~V}$ ) карбидкремниевых диодных размыкателей. Впервые эскпериментально оценена величина насыщенной скорости дрейфа дырок в $4 H-\mathrm{SiC} p$-типа: $v_{s p}=3 \cdot 10^{6} \mathrm{~cm} / \mathrm{s}$.

DOI: 10.21883/PJTF.2018.03.45572.17025

Импульсная электроника в современном мире обладает большим научно-техническим потенциалом. Мощные импульсные устройства необходимы в самых разнообразных областях, таких как сверхширокополосная радиолокация и связь, электромагнитное противодействие, ускорение заряженных частиц, томография, очистка жидких и газообразных сред, питание импульсных лазеров и др. Успешное развитие современных импульсных устройств и систем во многом обусловлено созданием эффективных генераторов коротких импульсов на кремниевой элементной базе [1-3]. 
В последние годы отечественными исследователями были начаты разработки импульсных диодов на основе карбида кремния политипа $4 H(4 H-\mathrm{SiC})$ [4-9]. 4H-SiC - это широкозонный полупроводниковый материал, который намного превосходит кремний по электронным и тепловым свойствам. Оценки показывают, что применение $4 H-\mathrm{SiC}$ может существенно улучшить основные характеристики генераторов: динамические параметры и тактовую частоту импульсов, удельную коммутируемую мощность. Кроме того, применение $4 \mathrm{H}-\mathrm{SiC}$ позволит радикально уменьшить габариты и массу импульсных устройств и повысить их надежность.

В настоящей работе продемонстрированы высоковольтные $(1600 \mathrm{~V})$ диодные размыкатели тока с субнаносекундным (150 ps) быстродействием на основе $4 H-\mathrm{SiC}$ и приведено краткое обсуждение их характеристик.

Диоды изготавливались на основе пластины $4 H$-SiC $n$-типа с выращенной на ней эпитаксиальной $p^{++}-p^{+}-p-n_{o}-n^{+}$-структурой (пластина была приобретена в компании Cree, Inc (CША) за счет средств гранта Российского научного фонда). Слои $p^{++}$и $p^{+}$имеют толщину $0.5 \mu \mathrm{m}$ и концентрацию акцепторов $2 \cdot 10^{19}$ и $5 \cdot 10^{18} \mathrm{~cm}^{-3}$ соответственно, $p$-слой обладает толщиной $6 \mu \mathrm{m}$ и концентрацией акцепторов $5 \cdot 10^{16} \mathrm{~cm}^{-3}, n_{0}$-слой имеет толщину $20 \mu \mathrm{m}$ и концентрацию доноров $5 \cdot 10^{15} \mathrm{~cm}^{-3}$, а $n^{+}$-слой - толщину $5 \mu \mathrm{m}$ и концентрацию доноров $1 \cdot 10^{18} \mathrm{~cm}^{-3}$.

Технология изготовления диодных чипов включала стандартные для постростовой технологии $4 \mathrm{H}$-SiC-приборов процессы: оптическую фотолитографию, напыление омических контактов к $p^{++}$-слою $(\mathrm{Al} / \mathrm{Ti})$ и к $n^{+}$-подложке $(\mathrm{Ni})$, вжигание контактов в вакууме при температуре $950^{\circ} \mathrm{C}$, травление меза-структур в плазме $\mathrm{SF}_{6}$ на глубину $15 \mu \mathrm{m}$, резку пластины на отдельные чипы размером $1.5 \times 1.5 \mathrm{~mm}$. Диаметр диодов составляет $0.8 \mathrm{~mm}$.

Для импульсных испытаний диодов была создана специальная схема (рис. 1). В данной схеме накачка диода осуществляется с помощью импульсного источника тока, который состоит из источника положительного (постоянного) напряжения $\left(V_{1}\right)$, накопительного конденсатора $\left(C_{1}\right)$, зарядных резисторов $\left(R_{1}\right.$ и $\left.R_{2}\right)$ и быстродействующего кремниевого $n$-канального МОП-транзистора ${ }^{1}(T)$. Испытываемый диод (DUT)

\footnotetext{
${ }^{1}$ МОП - металл-оксид-полупроводник.
} 


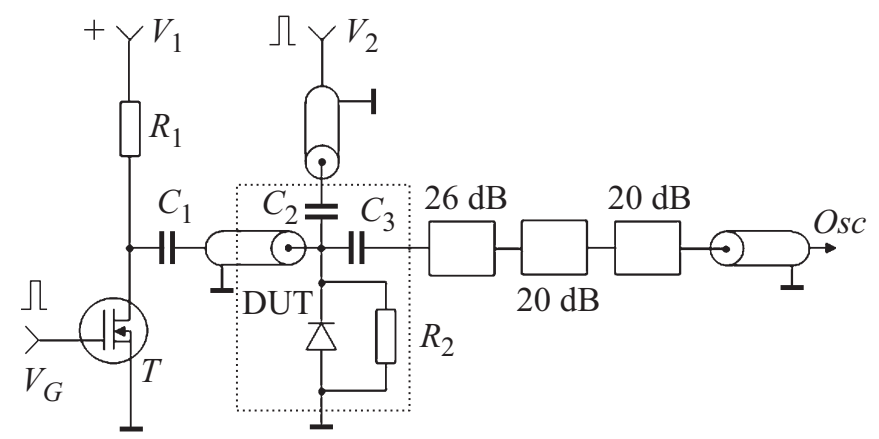

Рис. 1. Схема импульсных испытаний диодов. Пунктирной линией обведены элементы схемы, включенные в микрополосковую линию передачи.

включен в цепь разряда накопительного конденсатора. В исходном состоянии конденсатор $C_{1}$ заряжен до напряжения источника $V_{1}$. При включении транзистора положительным импульсом затвора $\left(V_{G}\right)$ через диод протекает импульс прямого тока, амплитуда и длительность которого задаются напряжением $V_{1}$, временем включения транзистора $T$ и временем разряда конденсатора $C_{1}$ через транзистор, коаксиальный кабель с волновым сопротивлением $50 \Omega$ и прямосмещенный диод. В экспериментах амплитуда импульсов прямого тока составляла до 10 A, а их длительность варьировалась в пределах 10-20 ns. Выкачка плазмы импульсом обратного тока осуществлялась с помощью импульсного генератора $V_{2}$, в качестве которого был использован стандартный генератор фирмы „Фидтехника“, выдающий на нагрузке $50 \Omega$ положительные импульсы с амплитудой до $5 \mathrm{kV}$, длительностью около $4 \mathrm{~ns}$ и фронтом нарастания около $2 \mathrm{~ns}$. Входной импульс обратного напряжения от генератора подается на диод в момент окончания импульса накачки через длинную линию с волновым сопротивлением $50 \Omega$ и развязывающий конденсатор $C_{2}$. Регистрирующая цепь включает развязывающий конденсатор $C_{3}$, высокочастотные аттенюаторы фирмы „Barth Electronics“ и цифровой осциллограф Tektronix DPO 70404C. Входное сопротивление аттенюаторов выполняет роль нагрузки $(50 \Omega)$, подключенной параллельно с диодом.

На рис. 2 показаны осциллограммы выходных импульсов. Кривая 1 записана при отключенном диоде, т.е. эта кривая повторяет форму

Письма в ЖТФ, 2018, том 44, вып. 3 


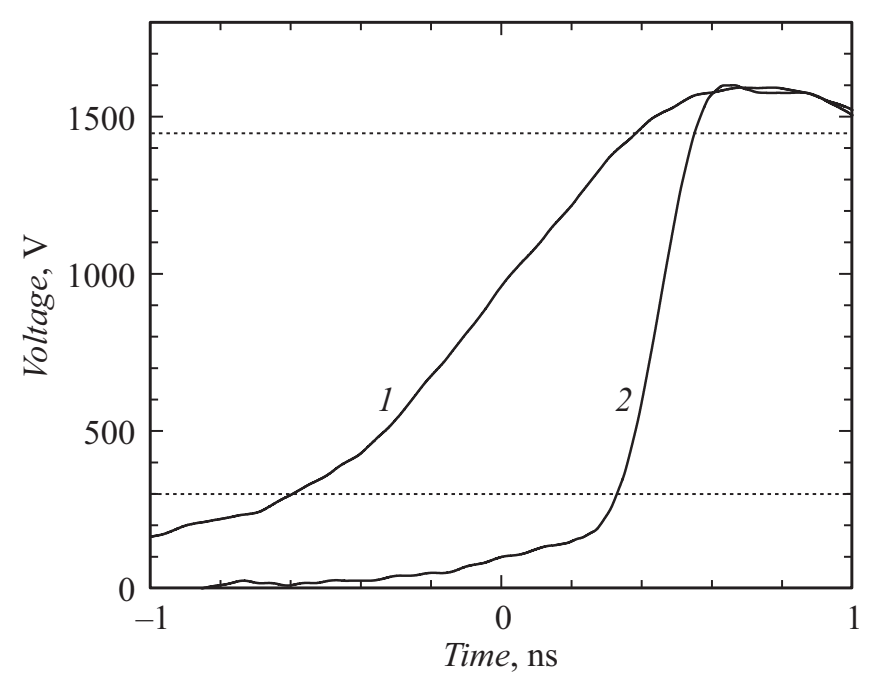

Рис. 2. Осциллограммы выходных импульсов: 1 - диод отключен, 2 - диод подключен.

входного импульса (амплитуда $1600 \mathrm{~V}$ и фронт нарастания около $2 \mathrm{~ns}$ ). Кривая 2 записана при подключенном диоде. При оптимальных параметpax накачки диод выполняет функцию обострителя переднего фронта входного импульса: до обрыва тока длинная линия зашунтирована на конце малым сопротивлением диода, а сразу после восстановления блокирующей способности диода генератор начинает работать на согласованную нагрузку $50 \Omega$.

На осциллограмме выходного импульса (кривая 2 на рис. 2) есть участок относительно медленного роста напряжения - так называемый „пьедестал“", величина которого достигает 200 V. Сразу за пьедесталом выходное напряжение резко поднимается до $1600 \mathrm{~V}$. Длительность фронта нарастания быстрого участка (размах $1150 \mathrm{~V}$ ) составляет $220 \mathrm{ps}$. Коэффициент обострения входного импульса составляет при этом около 10. Очевидно, что это регистрируемое время обрыва определяется помимо быстродействия диода также и полосой пропускания элементов регистрирующей цепи, включая микрополосковую линию и цифровой осциллограф (20 GHz-аттенюаторы искажений не вносят). Измеренное

Письма в ЖТФ, 2018, том 44, вып. 3 
нами время нарастания переходной характеристики микрополосковой линии равно 120 ps. Время нарастания переходной характеристики осциллографа с полосой пропускания $4 \mathrm{GHz}$ составляет 90 ps. С учетом этого рассчитанное время обрыва диодом тока равно $150 \mathrm{ps}$. Насколько нам известно, такое время является рекордно коротким для высоковольтных (свыше $1000 \mathrm{~V}$ ) карбидкремниевых размыкателей.

Наблюдаемый на осциллограмме выходного импульса пьедестал обусловлен падением напряжения на p-области диода при протекании обратного тока. К моменту начала обрыва тока сопротивление p-области становится максимальным вследствие двух причин: 1) р-область освобождается от инжектированных носителей; 2) скорость дрейфа равновесных дырок в этой области приближается к насыщенной. В этом случае насыщенная скорость дрейфа дырок $v_{s p}$ может быть рассчитана по формуле

$$
v_{s p}=\frac{I}{0.9 q p S}
$$

где $I$ - обрываемый ток, $q$ - элементарный заряд, $p$ - концентрация равновесных дырок в $p$-области, $S$ - площадь диода. При $I=32 \mathrm{~A}$ и $p=1.4 \cdot 10^{16} \mathrm{~cm}^{-3}$ (концентрация акцепторов $5 \cdot 10^{16} \mathrm{~cm}^{-3}$ ) рассчитанная по формуле (1) насыщенная скорость дрейфа дырок составляет $v_{s p}=3 \cdot 10^{6} \mathrm{~cm} / \mathrm{s}$. Отметим, что определенная таким образом насыщенная скорость дрейфа дырок в 5 раз меньше полученной нами ранее насыщенной скорости дрейфа электронов в $4 \mathrm{H}-\mathrm{SiC}$ [10].

В заключение можно отметить, что изготовленные карбидкремниевые диодные размыкатели приблизительно на порядок превосходят кремниевые дрейфовые диоды с резким восстановлением по времени обрыва тока (при сопоставимой блокирующей способности).

Исследование выполнено за счет гранта Российского научного фонда (проект № 14-29-00094).

\section{Список литературы}

[1] Грехов И.В., Месяи Г.А. // УФН. 2005. Т. 175. № 7. С. 735-744.

[2] Брылевский В.И., Смирнова И.А., Родин П.Б., Грехов И.В. // Письма в ЖТФ. 2014. Т. 40. В. 8. С. 80-87.

Письма в ЖТФ, 2018, том 44, вып. 3 
[3] Брылевский В.И., Рожков А.В., Смирнова И.А., Родин П.Б., Грехов И.В. // Письма в ЖТФ. 2015. Т. 41. В. 7. С. 1-7.

[4] Грехов И.В., Иванов П.А., Константинов А.О., Самсонова Т.П. // Письма в ЖТФ. 2002. Т. 28. В. 13. С. 24-29.

[5] Grekhov I.V., Ivanov P.A., Khristyuk D.V., Konstantinov A.O., Korotkov S.V., Samsonova T.P. // Solid State Electron. 2003. V. 47. N 10. P. 1769-1774.

[6] Грехов И.В., Кюрегян А.С., Мнащаканов Т.Т., Юрков С.Н. // ФТП. 2003. T. 37. B. 9. C. $1148-1151$.

[7] Иванов П.А., Коньков О.И., Самсонова Т.П., Потапов А.С., Грехов И.В. // ФТП. 2015. Т. 49. В. 1. С. $1558-1562$.

[8] АЯбанасьев А.В., Иванов Б.В., Ильин В.А., Кардо-Сысоев А.Ф., Лучинин В.В., Серков Ф.Б. // Сб. трудов Всерос. конф. „Микроэлектроника СВЧ“. СПб.: СПбГЭТУ, 2012. С. 260-262.

[9] Иванов М.С., Родин П.Б., Иванов П.А., Грехов И.В. // Письма в ЖТФ. 2016. T. 42. B. 1. C. $87-94$.

[10] Ivanov P.A., Potapov A.S., Samsonova T.P., Grekhov I.V. // Solid State Electron. 2016. V. 123. P. $15-18$ 